8 - ORIGINAL ARTICLE

MATERIALS TESTING

\title{
The biopolymer sugarcane as filling material of critical defects in rats $^{1}$
}

\author{
Taciana Cavalcanti de Abreu ${ }^{\mathrm{I}}$, Rodrigo Pontes de Lima ${ }^{\mathrm{II}}$, Veridiana Sales Barbosa de Souza ${ }^{\mathrm{III}}$, Olavio Campos Júnior ${ }^{\mathrm{IV}}$, Amanda \\ Vasconcelos de Albuquerque ${ }^{\mathrm{V}}$, José Lamartine de Andrade AguiarVI, Emanuel Sávio de Souza Andrade ${ }^{\mathrm{VII}}$, Belmiro Cavalcanti \\ do Egito Vasconcelos ${ }^{\mathrm{VI}}$
}

DOI: http://dx.doi.org/10.1590/S0102-865020160010000008

${ }^{I}$ Fellow PhD degree, Postgraduate Dentistry Program, Universidade de Pernambuco (UPE), Recife-PE, Brazil. Acquisition of data, technical procedures, manuscript preparation.

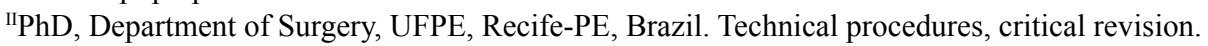

IIIMaster, Department of Surgery, Universidade Federal de Pernambuco (UFPE), Recife-PE, Brazil. Technical procedures, critical revision.

${ }^{\text {Iv }}$ Master, Assistant Professor, Department of Anatomy, UFPE, Recife-PE, Brazil. Macroscopic and histopathological examinations.

${ }^{v} \mathrm{PhD}$, Department of Surgery, UFPE, Recife-PE, Brazil. Manuscript preparation, critical revision.

${ }^{\mathrm{V}} \mathrm{PhD}$, Associate Professor, Department of Surgery, UFPE, Recife-PE, Brazil. Critical revision.

${ }^{\mathrm{VII}} \mathrm{PhD}$, Associate Professor, Department of Oral and Maxillofacial Surgery and Traumatology Subject, Pernambuco College of Dentistry, UPE, RecifePE, Brazil. Manuscript preparation, critical revision.

\section{ABSTRACT}

PURPOSE: To evaluate the effects of particulate (granule-shaped) SCB on bone repair relating it to its biocompatibility and bone neoformation.

METHODS: Thirty Wistar rats were submitted to a one 7-mm-diameter defect and divided equally into three experimental groups, with two different postoperative times of evaluation, 90 and 120 days. Each calvaria defect was filled up with clot (control group), particulated autogenous bone or granulated SCB. Five animals of each group were assessed at 90 and 120 days after surgery. In these two periods, histological and histometric analysis were obtained.

RESULTS: The clot group showed a bone resorption trend while the autogenous bone group a bone repair trend. However in the SCB group, the critical defect filled up only with fibrous connective tissue and presented none bone neoformation.

CONCLUSION: The sugarcane biopolymer when used in critical size defects was a biocompatible material and proved to be a good material to fill bone cavities, keeping them as uniform areas filled with soft tissue and avoiding the tissue shrinkage.

Key words: Biopolymers. Bone Regeneration. Bone Transplantation. Dental Implants. Rats. 


\section{Introduction}

Oral rehabilitation by implant dentistry in patients who have lost their teeth is becoming more frequent. However, these implants are possible only in highly absorbable areas where alveolar bone enough still exists. The alveolar bone requires functional stimuli generated by dental presence in order to maintain itself. When the tooth loss occurs, it triggers alveolar bone reabsorption. The rate and degree of this reabsortion vary according local and systemic factors and no typical reabsortion pattern has been stablished yet ${ }^{1,2}$.

Therefore, in order to make dental implant where reabsortion is in advanced state, the area must prior become absorbable again, be it either through increase in bone volume by vascularized, or not-vascularized, bone grafts or by guided bone regeneration (GBR) procedures. Autogenous bone graft techniques are considered gold standard treatment, though they present major disadvantages as bleeding, pain, nerve damage, infection and morbidity ${ }^{3}$. Also, autogenous bone is often not available in sufficient volume ${ }^{4}$. For those reasons, there have been many proposes for suitable bone substitutes for bone reconstruction surgeries ${ }^{4}$.

Demineralized bovine bone is one of the most well established among those substitutes. It presents osteoconductivity property, biocompatibility and its structure is similar to human bone $^{5}$. On other hand, calcium phosphate bone substitutes has been widely researched due to its mineral characteristic similar to human bone: it is bioactive, biodegradable and it presents osteoconductive properties, although not osteoinductivity ${ }^{6}$. Biphasic calcium phosphate (BCP) was more effective in bone defect repair in bone cavities when compared to hydroxylapatite (HA) only, $\beta$-tricalcium phosphate ( $\beta$-TCP) or blood clot $^{7}$.

The sugarcane biopolymer (SCB) shows physical and chemical characteristics suitable for prostheses manufacture since in its pure form SCB presents low toxicity, high biocompatibility, elasticity, tensile strength, flexibility and modelling capacity ${ }^{8-9}$ SCB demonstrated proper effects on different tissues causing integration with and remodelling of soft tissues ${ }^{10}$.

In critical bone defects on calvaria of Wistar rats, SCB
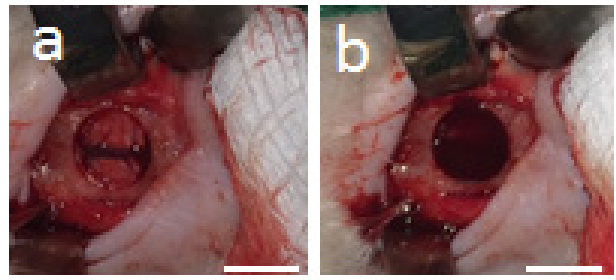

FIGURE 1 - Clinical photograph of the experiment madding a critical size defects in calvaria bone rats: a) empty critical size defect, b) filled up with autogenous clot; $\mathbf{c}$ ) filled up with particulated autogenous bone and $\mathbf{d}$ ) granulated biopolymer of sugarcane. Barrs $=7 \mathrm{~mm}$.
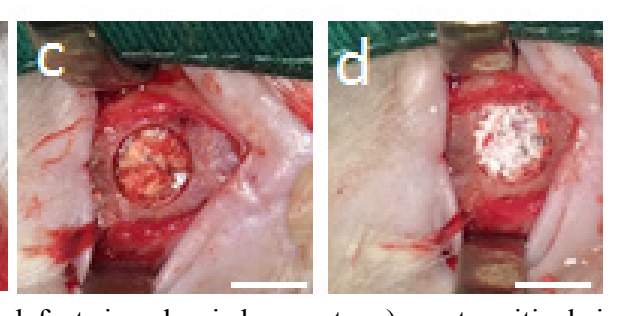

gel preparations associated with bone morphogenetic protein (BMP) showed to be a suitable scaffold for the BMP, presumably facilitating the controlled release of BMP during bone repair ${ }^{11}$.

Although some studies proposed SCB as a promising material for grafting and other medical procedures, none of those researches aimed bone grafting with granulated SCB to this date ${ }^{12-17}$. Therefore, this paper focused on the effects of particulate (granule-shaped) SCB on bone repair relating it to its biocompatibility and bone neoformation.

\section{Methods}

All procedures were approved by the Institutional Animal Bioethics Committee of the Center of Biological Sciences of UFPE, protocol number 23076.000193/2012-62.

Thirty healthy adult male Wistar rats were obtained from the vivarium of the Department of Antibiotics at the Federal University of Pernambuco (UFPE) and housed at its facilities under a $12 \mathrm{~h}$ light: $12 \mathrm{~h}$ darkness photoperiod and allowed food and water ad libitum.

\section{The sugarcane biopolymer}

The biopolymer was produced and supplied by Polisa ${ }^{\circledR}$, Biopolymers for Health Ltda, linked to the Federal Rural University of Pernambuco (UFRPE). Comparative observational studies in animals between the polymer and other materials, commonly used in humans, showed biopolymer superiority, although even without data for completion of statistical studies ${ }^{18,19}$.

\section{Study design}

Thirty healthy Wistar rats were divided equally into three groups. One critical defect with size $7 \mathrm{~mm}$ diameter was created in the calvaria of each of the animals (Figure 1). The defects were filled with grafts, according to the composition of the groups studied as follow: either control group filled with autogenous clot $(\mathrm{AC})$; or autogenous bone graft $(\mathrm{AB})$ or granulated biopolymer group (SCB). Five animals of each group were euthanized after 90 days and five after 120 days. 


\section{Surgical protocol}

The animals were anesthetized with an intramuscular (IM) injection of a mixture of ketamine hydrochloride $(50 \mathrm{mg} / \mathrm{kg})$ and xylazine $(20 \mathrm{mg} / \mathrm{kg})$. Before the surgery procedure all animals had received an IM, prophylactic, antibiotic therapy of cephalosporin $(10 \mathrm{mg} / \mathrm{Kg})$. The surgical site was shaved and then wiped with $2 \%$ chlorhexidine. An incision was made along the sagittal midline from the frontal bone to the occipital bone. The circular defect was then created in each animal using 7-mm trephine under cool saline irrigation. The resected bone was gently removed and powdered. The defects were filled according to the group studied, of which the control defect was filled with blood clots (Figure 1). The soft tissue was repositioned and then sutured layer by layer using 4.0 Mononylon sutures Ethicon-Johnson ${ }^{\circledR}$ and a painkiller dipirone $(10 \mathrm{mg} / \mathrm{Kg})$ was injected IM. Animals were carefully observed for inflammation, allergic reactions, and other complications around the surgical site throughout the healing period. Then the rats were sacrificed using an overdose of anesthetic at either 90 days $(\mathrm{N}=5)$ or 120 days $(\mathrm{N}=5)$ postsurgery.

\section{Histologic processing}

Block sections including the surgical sites were removed when the animals were sacrificed. The sections were fixed in $10 \%$ buffered formalin for 10 days after rinsing with sterile saline. Then, the sections were decalcified in 5\% formic acid for 15 days and then embedded in paraffin. Semi-serial sections ( $5 \mu \mathrm{m}$ thickness) were cut through the center of the circular calvarial defects and stained with hematoxylin and eosin for microscopic analysis.

\section{Histological analysis}

The specimens were examined under a microscope (Axio Imager $\mathrm{M} 2 \mathrm{~m} /$ Zeiss) equipped with a camera (AxioCam $\mathrm{HRc}$ / Zeiss) by one blinded examiner. Images of the slides were acquired and saved as digital files. The presence of the inflammatory infiltrate, foreign body reaction, fibrous tissue and newly formed bone (osteoid and mature bone) were analyzed under optical microscopy. According to the tissue repair in the critical size defect, the animals were assigned as: soft tissue; partial bone closure or total bone closure.

\section{Histometric analysis}

After conventional microscopic examination, computerassisted histometric measurements in the calvarial defect were performed according to preview study ${ }^{7}$ using an automated image analysis system (Image-Pro Plus; Media Cybernetics, Silver Spring, MD). Three parameters were measured by one blinded examiner: the area of total augmentation (in $\mu \mathrm{m}^{2}$ ), the area of new bone (in $\mu \mathrm{m}^{2}$ ) and the area of soft tissue (in $\mu \mathrm{m}^{2}$ ). The area of total augmentation includes all tissues (newly formed bone, biopolymer residual particles when present, fibrous tissue and vascular tissue) within the boundaries of defects. Only the area with newly formed mineralized bone was measured as the new bone area and the soft area was the difference between them.

\section{Statistical analysis}

The statistical analysis was performed using a commercially available software program (SPSS 22.0, SPSS, Chicago, IL). Histomorphometric records from the calvarial defect samples were used to calculate the mean and standard deviation values (SD) of groups. The data were examined with the Kolmogorov-Smirnov test for conformance to a normal distribution. Analysis of variance was used to analyze the effects of time and experimental conditions. The ANOVA followed by post-hoc Tukey test were used to analyze differences between the groups. A two sample $t$ test was carried out to analyze the differences in parameters between the 90 and 120-postoperative days. The level of statistical significance was set at $\mathrm{p}<0.05$.

\section{Results}

\section{Clinical findings}

Healing during the postoperative period was uneventful for all animals. The granulated biopolymer seems to offer the same biocompatibility presented in previous studies once no complications were found (i.e., inflammatory reactions or allergic reactions).

\section{Histologic findings}

In the AC group, $40 \%$ of the animals have shown the defect areas partially closed with new bone tissue at 90 days, and the same amount (40\%) totally closed with new bone tissue at 120 days (Tables 1 and 2). A thin layer of new bone formed in the 90 days group, while a thicker layer of new bone was seen in the 120 days group around both defect margins [Figures $2(\mathrm{~A}, \mathrm{~B})$ and 3 $(\mathrm{A}, \mathrm{B})]$. 
In the $\mathrm{AB}$ group $100 \%$ of the animals had the defect area filled with new bone tissue (some of them are partially closed and some totally closed). The particulated autogenous bone induced a considerable amount of new bone formation in the defect area after 90 days weeks of postoperative healing and after 120 days, there was a bone formation increasing, shown by a thicker layer [Figures 2 (C,D) and 3 (C,D)].

As expected the SCB group at 90 or 120 days after surgery have shown connective tissue and numerous new blood vessels filling the majority of the defects within the biopolymer. The inflammatory reaction triggered by the biopolymer was clearly higher when compared with others groups, with also a polymorphonuclear mainly type cells. However, the presence of granulated SCB had avoided the old bone tissue shrinkage. Although there was no bone new formation, the healing process was well established, with the presence of fibrosis in both time frames [Figures $2(\mathrm{E}, \mathrm{F})$ and $3(\mathrm{E}, \mathrm{F})]$.

TABLE 1 - Critical size defect closure at 90 days of postoperative healing.

\begin{tabular}{ccccccc}
\hline & \multicolumn{1}{c}{ Clot } & \multicolumn{2}{c}{$\begin{array}{c}\text { Autogenous } \\
\text { Bone }\end{array}$} & \multicolumn{2}{c}{ SCB } \\
\hline $\begin{array}{c}\text { Type of tissue } \\
\begin{array}{c}\text { Connective tissue } \\
\text { closure }\end{array}\end{array}$ & 3 & 60 & - & - & 5 & 100 \\
$\begin{array}{c}\text { Partially new bone } \\
\text { closure }\end{array}$ & 2 & 40 & 4 & 80 & - & - \\
$\begin{array}{c}\text { Total new bone } \\
\text { closure }\end{array}$ & - & - & 1 & 20 & - & - \\
Total animals & 5 & 100 & 5 & 100 & 5 & 100 \\
\hline
\end{tabular}

SCB: Sugarcane Biopolymer.

TABLE 2 - Critical size defect closure after 120 days of postoperative healing.

\begin{tabular}{ccccccc}
\hline & \multicolumn{3}{c}{ Clot } & \multicolumn{2}{c}{$\begin{array}{c}\text { Autogenous } \\
\text { Bone }\end{array}$} & \multicolumn{2}{c}{ SCB } \\
\hline $\begin{array}{c}\text { Type of tissue } \\
\text { Connective tissue } \\
\text { closure }\end{array}$ & 3 & 60 & - & - & 5 & 100 \\
$\begin{array}{c}\text { Partially new bone } \\
\text { closure }\end{array}$ & - & - & 5 & 100 & - & - \\
Total new bone closure & 2 & 40 & - & - & - & - \\
Total animals & 5 & 100 & 5 & 100 & 5 & 100 \\
\hline
\end{tabular}

SCB: Sugarcane Biopolymer.
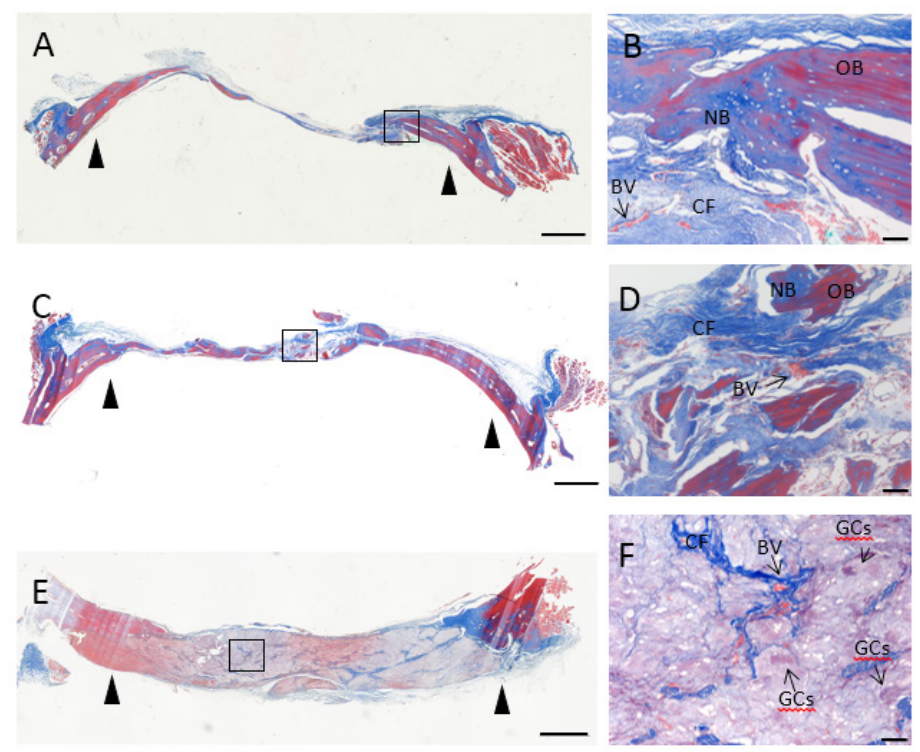

FIGURE 2 - Representative photomicrographs obtained at 90 days postoperative. (A,B) Control group; (C,D) Autogenous bone group; (E,F) Sugarcane biopolymer group. Bars $=1000 \mu \mathrm{m}$ and 50 $\mu \mathrm{m}$. Arrowheads $=$ defect margin $; \mathrm{NB}=$ new bone; $\mathrm{OB}=$ original bone; $\mathrm{CF}=$ collagenous fiber; $\mathrm{BV}=$ blood vessels; $\mathrm{GCs}=$ multinuclear giant cells.

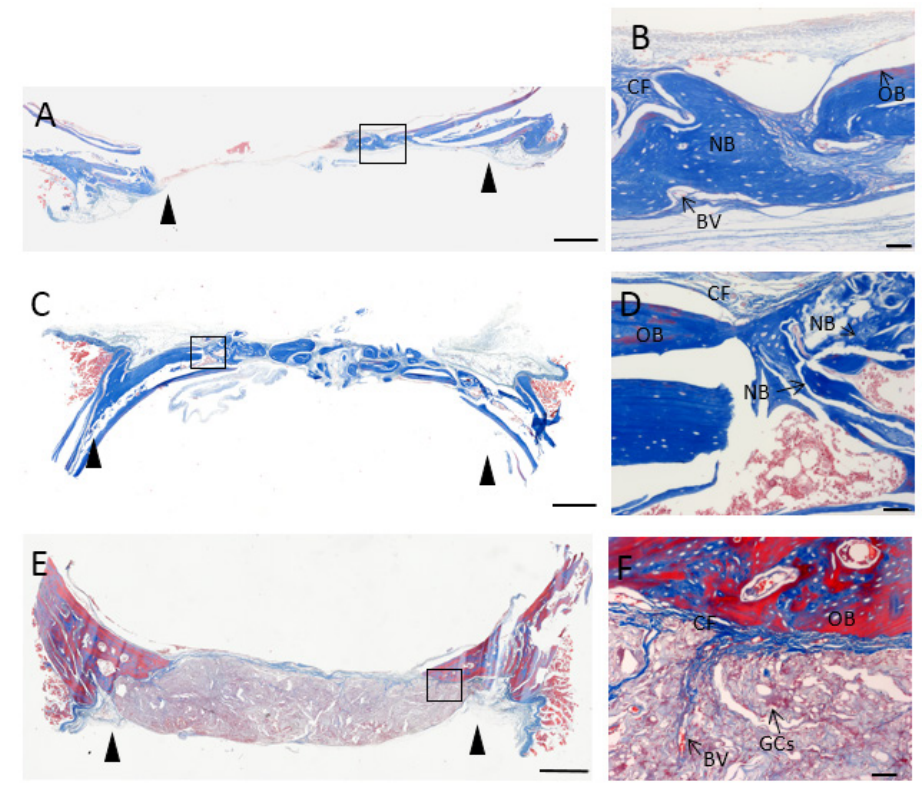

FIGURE 3 - Representative photomicrographs obtained at 90 days postoperative. $(\mathbf{A}, \mathbf{B})$ Control group; $(\mathbf{C}, \mathbf{D})$ Autogenous bone group; (E,F) SCB group. Bars $=1000 \mu \mathrm{m}$ and $50 \mu \mathrm{m}$. Arrowheads $=$ defect margin $; \mathrm{NB}=$ new bone $\mathrm{OB}=$ original bone; $\mathrm{CF}=$ collagenous fiber; $\mathrm{BV}=$ blood vessels; $\mathrm{GCs}=$ multinuclear giant cells . 


\section{Histometric findings}

The histometric measurements are summarized in Table 3. Throughout our observations, the area of total augmentation (in $\mu \mathrm{m}^{2}$ ) - including all tissues within the boundaries of defects - were the same $(p \geq 0.05)$ when the two times of evaluation were compared within the same experimental group. However the SCB presence induced a considerable defect area increasing when compared with $\mathrm{AC}$ or $\mathrm{AB}$ group $(\mathrm{p} \leq 0.05)$ in both time frames.

The area of new bone (in $\mu \mathrm{m}^{2}$ ) was greater in $\mathrm{AB}$ group than in AC group at 90 days postoperative $(p=0.04)$, but this pattern did not repeat at 120 days $(\mathrm{p}=0.10)$. As mentioned early, there was not observed any new bone formation in SCB group. When the two time frames were compared it was not found any difference within the same experimental group.

The area of soft tissue was the same between 90 and 120 days and when different groups were compared. Because there was no new bone formation to be excluded from the total area of augmentation it was not possible to measure the soft area in SCB group. However, it was clear that the soft tissue was also involved with residual particles of SCB.

TABLE 3 - Histometric measurements $-\left(10^{-6}\right) \mu \mathrm{m}^{2}$ (Mean \pm SD).

\begin{tabular}{|c|c|c|c|c|c|}
\hline \multirow{2}{*}{ Variable } & \multirow{2}{*}{ Time } & \multicolumn{3}{|c|}{ Groups } & \multirow{2}{*}{ P-Value } \\
\hline & & $\mathbf{A C}$ & AB & SCB & \\
\hline \multirow{3}{*}{ Area of total augmentation } & 90 days $^{4}$ & $1.78 \pm 0.63^{\mathrm{a}}$ & $2.67 \pm 0.65^{\mathrm{a}}$ & $9.80 \pm 3.63^{b}$ & $0.001^{1}$ \\
\hline & 120 days $^{4}$ & $2.20 \pm 0.22^{\mathrm{a}}$ & $3.40 \pm 0.99^{\mathrm{a}}$ & $8.90 \pm 3.31^{b}$ & $0.005^{1}$ \\
\hline & p-Value & 0.74 & 0.40 & 0.30 & - \\
\hline \multirow{3}{*}{ Area of new bone } & 90 days & $0.56 \pm 0.52$ & $1.46 \pm 0.39$ & - & $0.04^{2}$ \\
\hline & 120 days & $0.90 \pm 0.29$ & $1.42 \pm 0.30$ & - & $0.10^{2}$ \\
\hline & p-Value & 0.33 & 0.86 & - & - \\
\hline \multirow{3}{*}{ Area of soft tissue } & 90 days & $1.22 \pm 0.57$ & $1.21 \pm 0.52$ & - & $0.20^{2}$ \\
\hline & 120 days & $1.30 \pm 0.25$ & $1.98 \pm 0.64$ & - & $0.61^{2}$ \\
\hline & p-Value & 0.33 & 0.24 & - & - \\
\hline
\end{tabular}

AC: Autologous clot; AB: Autologous bone; SCB: Sugarcane Biopolymer. 1 - p-value of the analysis of variance (ANOVA). 2 - P-value of Student t-test for independent samples, comparison between the groups. 3 - p-value of Student t-test for independent samples, comparison between the times. 4 - Values - on same row - followed by different letters showed statistically significant differences between groups, through Tukey's test.

\section{Discussion}

This work aims to contribute to current state of the art for filling agents used as grafts. For this purpose, SCB filling characteristics and use outcome were compared to those presented by only blood clot or autogenous bone, as the latter is the gold standard for bone grafting ${ }^{20}$.

For this study, we elected the model of induced critical defects since it emulates situations where bone osteogenic potential cannot surpass the defect and the repair can only be accomplished through graft instead. This work used the model of induced circular defects in rat calvaria. The defects spanned $7 \mathrm{~mm}$ diameter and intended to eliminate spontaneous bone repair as some works used $7 \mathrm{~mm}$ or $5 \mathrm{~mm}$ wide defects ${ }^{7,12}$. Nevertheless, $40 \%$ of animals of the clot group (AC) presented neoformed bone tissue, both for 90 and 120 postsurgery days subgroups. Although other studies did not found the same histological findings ${ }^{7,12}$, we suggest performing wider critical defects for future researches. From an anatomical point of view, there is no hindrance to performing up to $10 \mathrm{~mm}$ wide critical defect in rat calvaria.
The absence of major inflammatory response in histological findings as well as no signals of inflammatory or allergic reactions for grafting rejection for SCB group proved once again the SCB biocompatibility as described in previous works ${ }^{8,9}$.

Granule-shaped SCB presented also a distinctive feature during trans-operative period. Although not assessed in an extensive manner, SCB presented hemostatic capability. Granule-shaped biopolymer caused reduction in surgical bleeding and facilitated viewing of edges of the defect. Previous researches agreed that property might occurs through mechanical obstruction ${ }^{10}$, therefore that property should be more studied in future works.

Concerning histological and histometric findings, the autogenous bone group (AB), considered gold standard, showed significant difference compared to clot group (AC) and SCB group for osteogenic process at 90 days subgroups. For that analysis, AC showed no trends towards bone formation, $\mathrm{AB}$ presented critical defect repair for all animals, whilst every animal in SCB group exhibited uniform fibrous connective tissue neoformation. The result obtained for $\mathrm{AB}$ is consistent with current literature ${ }^{21}$.

The fibrous connective tissue was present within the 
critical defect in all animals of SCB group, for both 90 days and 120 days. A possible explanation for the neoformation is that the absence of a physical barrier, as a membrane, might interfere with osteoneogenesis process due to prior connective tissue infiltration. Some works use periosteum as barrier to avoid that infiltration ${ }^{13}$, as did this work, but this barrier was not effective. We suggest that barrier could therefore be made of non-autogenous or artificial materials.

\section{Conclusions}

The sugarcane biopolymer is a biocompatible material, suitable for filling critical size bone defects with soft tissue. Therefore, that area must not undergo great tensions or pressures. It should be used to keep the area uniform and avoid tissue shrinkage so that it maintains uniform physical appearance as for prosthetic aesthetics.

\section{References}

1. Araújo MG, Lindhe J. Dimensional ridge alterations following tooth extration. An experimental study in the dog. J Clin Periodontol. 2005;32(2):212-8. PMID: 15691354.

2. Wang RE, Lang NP. Ridge preservation after tooth extration. Clin Oral Implants Res. 2012;23(Suppl 6):147-56. PMID: 23062139.

3. Sbordone L, Toti P, Menchini-Fabris GB, Sobordone C, Piombino P, Guidetti F. Volume changes of autogenous bone grafts after alveolar ridge augmentation of atrophic maxillae and mandibles. Int $\mathrm{J}$ Oral Maxillofac Surg. 2009;38:1059-65. PMID: 19632815.

4. Schliephake H, Zghoul N, Jäger V, van Griensven M, Zeichen J, Gelinsky M. Bone formation in trabecular bone cell seeded scaffolds used for reconstruction of the rat mandible. Int J Oral Max Surg. 2009;38(2):166-72. PMID: 19121923.

5. Pripatnanont $P$, Nuntanaranont $T$, Vongvatcharanon. Proportion of deproteinized bovine bone and autogenous bone affects bone formation in the treatment of calvarial defects in rabbits. Int J Oral Maxollofac Surg. 2009;38(4):356-62. PMID: 19278833.

6. Blokhuis TJ, Chris Arts JJ. Bioactive and osteoinductive bone graft substitutes: Definitions, facts and myths. Injury. 2011;42 Suppl 2:S26-9. PMID: 21714968

7. Hwang JW, Park JS, Lee JS, Jung UW, Kim CS, Cho KS, Lee YK, Choi SH. 2012. Comparative evaluation of three calcium phosphate synthetic block bone graft materials for bone regeneration in rabbit calvaria. J Biomed Mater Res Part B. 2012;100(8):2044-52. PMID: 22865716.

8. Paterson-Beedle M, Kennedy JF, Melo FAD, Lloyd LL, Medeiros VA. Cellulosic exopolysaccharide produced from sugarcane molasses by a Zoogloea sp. Carbohyd Polym. 2000;42(4):375-83. doi: 10.1016/S0144-8617(99)00179-4.

9. Tavares LHM, Vilar FO, Aguiar JL, Paz AR, Melo FAD, Negromonte GRP. Biopolymer sponge for high grade renal trauma: an experimental study in rabbits. Open J Urol. 2014;4(1):1-6. doi: 10.4236/oju.2014.41001.

10. Falcão SC, Evencio Neto J, Coelho AR. Incorporation by host tissue of two biomaterials used as repair of defects produced in abdominal wall of rats. Acta Cir Bras. 2008;23(1):78-83. PMID: 18278397.

11. Medeiros Júnior MD, Carvalho EJA, Catunda IS, Araújo SB, Aguiar JLA. Hydrogel of polysaccharide of sugarcane molasses as carrier of bone morphogenetic protein in the reconstruction of critical bone defects in rats. Acta Cir Bras. 2013;28(4):233-8. PMID: 23568229.

12. Coathup MJ, Hing KA, Samizadeh S, Chan O, Fang YS, Campion C, Buckland T, Blunn GW. Effect of increased strut porosity of calcium phosphate bone graft substitute biomaterials on osteoinduction. J Biomed Mater Res A. 2012;100(6):1550-5. PMID: 22419568.

13. Hallman M; Thor A. Bone substitutes and growth factors as an alternative/complement to autogenous bone for grafting in implant dentistry. Periodontol. 2008;47:172-92. PMID: 18412581.

14. Fragoso AS, Silva MB, de Melo CP, Aguiar JL, Rodrigues CG, de Medeiros PL, Branco Junior JF, Andrade CA, Oliveira MD. Dielectric study of the adhesion of mesenchymal stem cells from human umbilical cord on a sugarcane biopolymer. J Mater Sci Mater Med. 2014;25(1):229-37. PMID: 24072391.

15. Vasconcelos SJ, Leão RA, Bernardino-Araújo S, Lira MM, Tsuji DH. Effect of sugarcane biopolymer in vocal fold of rabbits. Comparative study with calcium hydroxyapatite. Acta Cir Bras. 2015;30(3):186-93. PMID: 25790006.

16. Aguiar JL, Lins EM, Marques SR, Coelho AR, Rossiter R de O, Melo RJ. Sugarcane biopolymer patch in femoral artery angioplasty on dogs. Acta Cir Bras. 2007;22(Suppl 1):77-81. PMID: 17505660.

17. Albuquerque PCVC, Santos SM, Aguiar JLA, Pontes Filho N, Mello R JV, Costa MLCR, Olbertz CMCA, Almeida TMS, Santos AHS, Silva JC. Comparative macroscopic study of osteochondral defects produced in femurs of rabbits repaired with biopolymer gel cane sugar. Rev Bras Ortop. 2011;46(5):577-84. doi: 10.1590/ S0102-36162011000500016.

18. Martins AGS, Lima SVC, Araujo LAP, Vilar F O, Cavalcante NTPL. A new dressig for hypospadias surgery. Int Braz J Urol. 2013;39:408-13. doi: 10.1590/S1677-5538.IBJU.2013.03.15.

19. Cordeiro-Barbosa FDA, Aguiar JLDA, Lira MMDM, de Pontes Filho NT, Bernardino-Araújo S. Use of a gel biopolymer for the treatment of eviscerated eyes: experimental model in rabbits. Arq Bras Oftalmol. 2012;75(4):267-72. doi: 10.1590/S000427492012000400010.

20. Hannink G, Chris Arts JJ. Bioresorbability, porosity and mechanical strength of bone substitutes: what is optimal for bone regeneration? Injury. 2011;42:S25-2. PMID: 21714966.

21. Calori GM, Mazza E, Colombo M, Ripamonti C. The use of bonegraft substitutes in large bone defects: any specific needs? Injury. 2011;42:S56-63. PMID: 21752369.

\section{Correspondence:}

Belmiro Cavalcanti do Egito Vasconcelos

Universidade de Pernambuco

Avenida General Newton Cavalcanti, 1650

54753-220 Camaragibe - PE Brasil

belmiro@pq.cnpq.br.

Received: Sept 03, 2015

Review: Nov 08, 2015

Accepted: Dec 07, 2015

Conflict of interest: none

Financial source: none

${ }^{1}$ Research performed at Experimental Surgery Center, Universidade Federal de Pernambuco (UFPE), Recife-PE, Brazil. 